\title{
Determination of Mobile Phone Tracking using Various Softwares
}

\author{
Shaveta Bhatia \\ Assistant Professor \\ Manav Rachna International \\ University, Faridabad
}

\author{
Saba Hilal, PhD. \\ Professor \\ School of Computer Sciences \\ Lingayas University,Faridabad
}

\begin{abstract}
One of the important features of Communication System is to find the Location of a Person. Finding the location of Person is either through Internet or through Mobile Devices. Most of the valuable location-based services are enabled by this feature of Location Tracking. There are various Location technologies which can be used and implemented by telecommunication managers and engineers. The technologies are GPS, GPRS, and WiFi with android operating Systems. Location can also be searched without GPS through Internet. The paper briefly discussed GSM network and cellular data networks from point of view of IP Clients, used for finding location of mobile phone. Further, a paper determined the location through IPaddress, through mobile Number, through SMS, through facebook and also through google latitude. Finally the study compares the result that leads to conclusions and key issues for further research.
\end{abstract}

\section{Keywords}

SMSTracker, GPS, Google Latitude, GSM, Facebook.

\section{INTRODUCTION}

In today's environment, a mobile has become one of the important necessities. If a person wants to search his family member or a child or if a person who loses his mobile wants to track it, or a Person wants to know who is disturbing him by giving missed calls or irrelevant SMS, a person becomes handicapped if he is unable to get in touch with the contacts. With the help of GSM technology, it is possible to trace and find the Location of person with the help of $2 \mathrm{G}$ and $3 \mathrm{G}$ mobile phones which the other person is using. There are many applications on the internet through which one can detect the location of user. These applications include survillence, detection of fraud, help in business marketing etc. There are two types of addresses that are assigned to user i.e. public IP addresses and private IP addresses for data distribution and performance tuning of a System [5]. One can also find the Location of user through IP address for immediate or any specific service. A few data services such as Maxmind [4] are provide that maintains the tables including IP addresses with the locations that matches. The important requirement of general user is to get the Location of his family member. This can be done through sending and receiving SMS.The Paper describes the general architecture of GSM and an IP cellular Network to determine the location of user. In further Sections, a paper will determine various methods of Location Tracking and compare their results.

\section{RELATED WORK}

The authors in [1] proposed and implemented an intelligent train tracking and management system to improve the existing railway transport service. The provided System is a combination of mobile computing, Global System for Mobile Communication (GSM), Global Positioning System (GPS), Geographical Information System (GIS) technologies and software. The location of Train with Maximum accuracy is done through inbuilt GPS System and this result is send to the Central System through GSM . The information about the train location helps the train Controller to take right decisions regarding the further proceeding of Train. The data is processed and provided through maps. Location information through this system helps to facilitate accurate scheduling with regard to train arrival and departure on each station.

The Researchers in [2] proposed and developed a system where the complaints of the drivers on the roads are easily accessible .The system is implemented with the help of GSM.This System is convenient channel for drivers to send complaints regarding public infrastructure so that better services are provided to the public. The implementation of procedure for road maintenance is done with the combination of GPS and GSM technologies.

The authors in [11] proposed and implemented NNSS algorithm which is based on recording and processing real time signal strength information available at multiple base stations positioned to provide overlapping coverage in the area of interest. This algorithm provides calculates the accuracy of user location. With the help of signal strength gathered by various users coordinates. this algorithm is successful for outdoors not for indoors.

A Researcher in [12] discussed the implementation of simple and cost effective system that help users to track College friends and colleagues within campus environment. This system locates the college friends using Bluetooth and WIFI connectivity on mobile phones. A mobile phone is loaded with software that communicates with the Server. This work is implemented through GSM. The server gives the current location of moving users.

The authors in [13] proposed an integrated GPS-GSM system used to Track vehicles using Google Earth Application. The main goal of the system is Automobile Trajectory used to assist corporations with large number of automobiles and several usage purposes. To provide location and time information in a system, Global positioning system is used as space based global navigation satellite system [7]. The performance of this integrated system is calculated with the help of map matching techniques used for automobiles localization. The system shows proper travel routes from the beginning of Journey.

\section{GLOBAL SYSTEM FOR MOBILE COMMUNICATION}

Kuboye[16] defined Global system for mobile communications (GSM) as a digital cellular network which handles more users than the analog cellular network. This communication help mobile operators to get the details of 
mobile user when he or she moved into the roaming area i.e goes out of coverage area of tower. The data transmission speed of GSM is $40 \mathrm{Kbps}$. The various data services like bhartiya mobiles and Mobiletrace, all uses the GSM to locate the mobile User. Peter Rysavy research [17] said "The wide acceptance of GSM is due to its features such as quality, capacity, covience, reduction in traffic and roaming". Figure 1 describes the architecture of GSM with the functioning of various components.

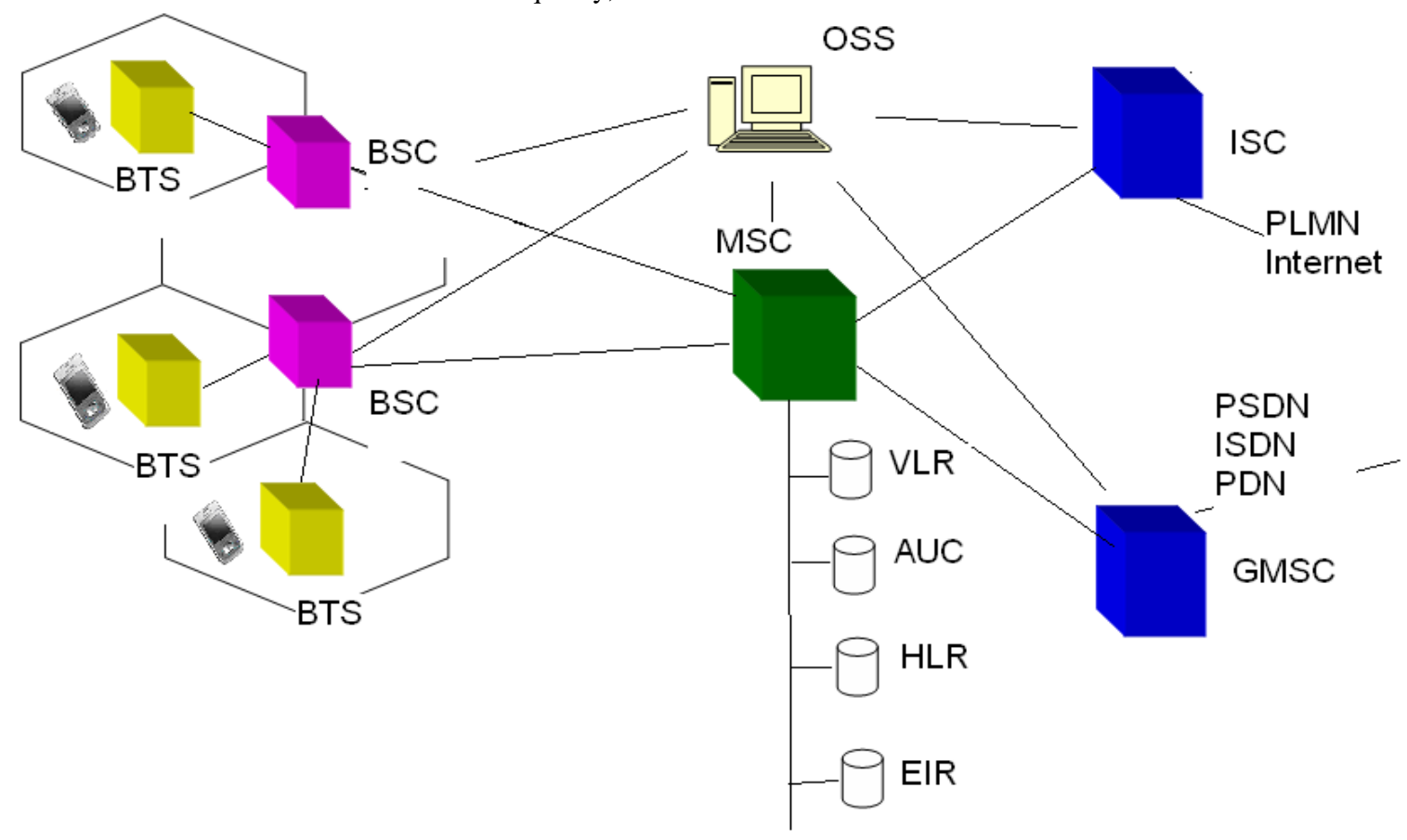

Fig 1: Architecture of Global System for Mobile Communication

\subsection{Base Station Subsystem}

The base station subsystem (BSS) is defined as "the section of a traditional cellular telephone network which is responsible for handling traffic and signaling between mobile phone and network switching subsystem [3]". BSS consist of two parts: Base Transceiver station (BTS) and Base Station controller (BSC) where BTS is a Tower that communicates with all mobile stations comes in its range.BSC controls all BTS in the network.

\subsection{Network switching Subsystem (NSS)}

The System is responsible for enabling and disabling connections between various mobile phones.it also provides authentication to various mobile users.It maintains the database of all enabled mobile users .The database includes Home Location register that stores the information of local users, Visitor Location register that stores information of roaming users, Authentication register, stores information of authentications provided to various users and equipment identity register that stores information of International Mobile equipment.. There is Mobile Switching Center in the architecture which is heart of network and responsible for overall communication.

\subsection{OSS(Operation and Support System)}

This is a Center and basic unit from where Network operators monitor and control the overall system.

The Locations of User on different Mobiles at different places are plotted on a map and hence Client can be traced out more easily. For more accurate results, the device is enabled with assisted GPS. The next section gives the results of Location of mobile users using different Softwares.

\section{VARIOUS SOFTWARES FOR LOCATION TRACKING WITH TEST CASES}

This Section shows and compare the results of Location Tracking through various softwares.Some of them only provides the Subscriber Identity or the Location from where phone is subsribed.Others gives real Location of users in particular city and area. Some Locations are also shown through facebook according to the online entered contact place. There are six subsections which shows the result.

\subsection{Location Tracking through IP Address}

The various IPAddresses are tested to get the Location through GeoIPLocation Service [8].Some of the test cases with results are shown below:- 
Testcase 1:IPAddress:116.202.92.248

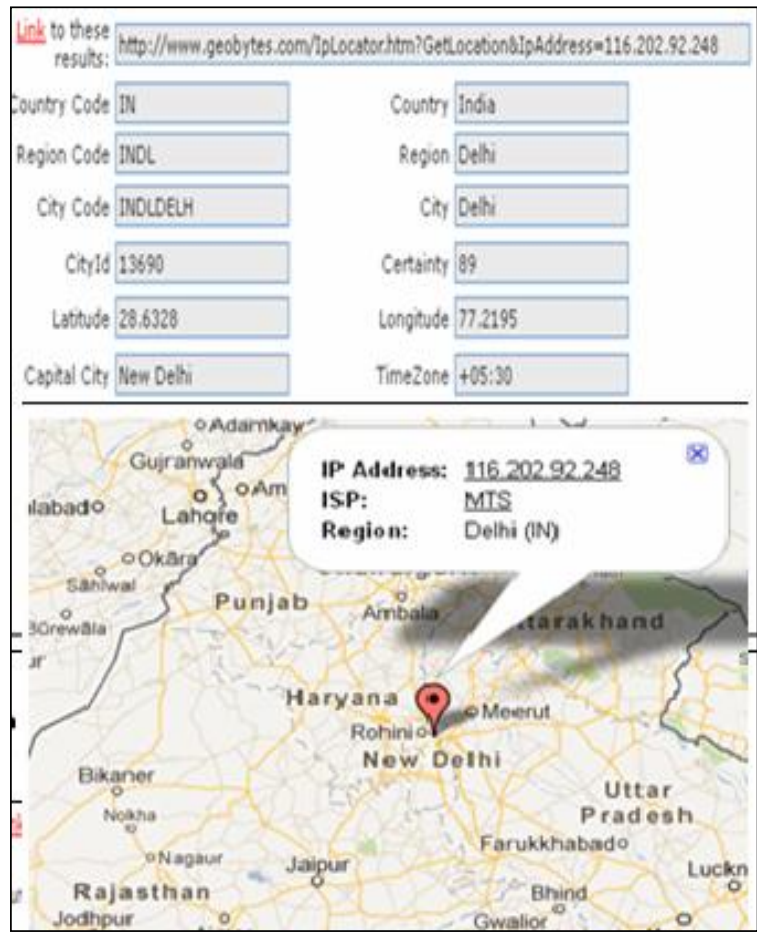

Fig 2: The Location including Longitude, Latitude, name of ISP service provider and city for given IP address. The Location is also shown using Google maps [18].

\section{Test Case 2: IP Address: 115.245.255.217}

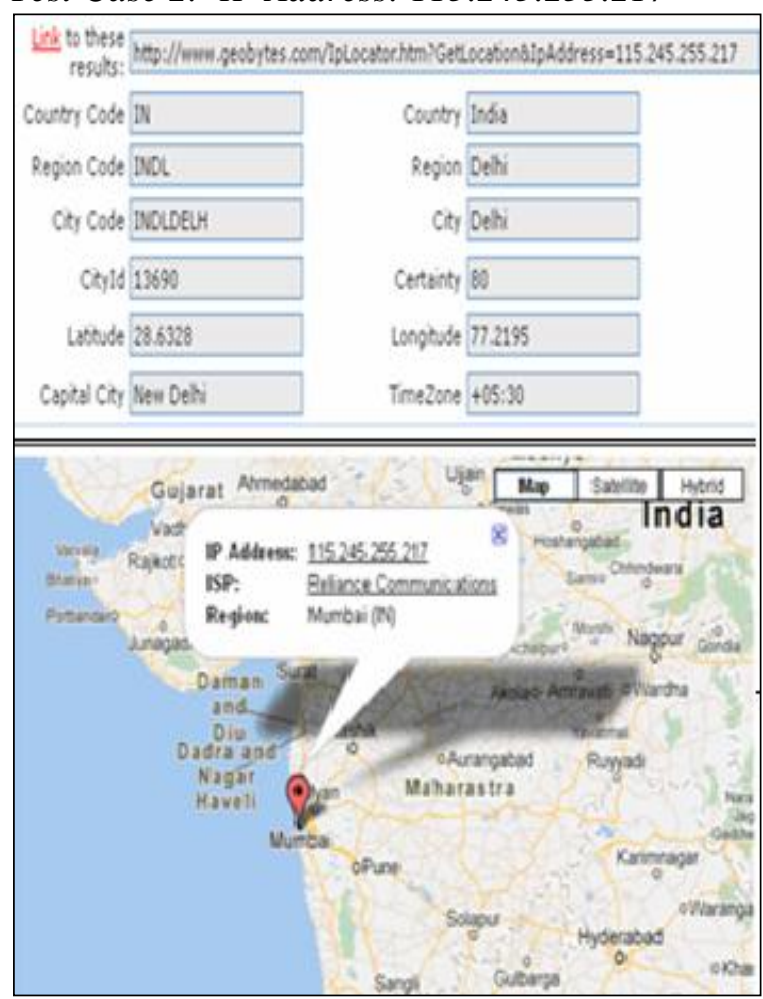

Fig 3: The Location including Longitude, Latitude, name of ISP service provider and city for given IP address. The Location is also shown using Google maps [18]
Test case 3: IP Address: 135.123.145.118

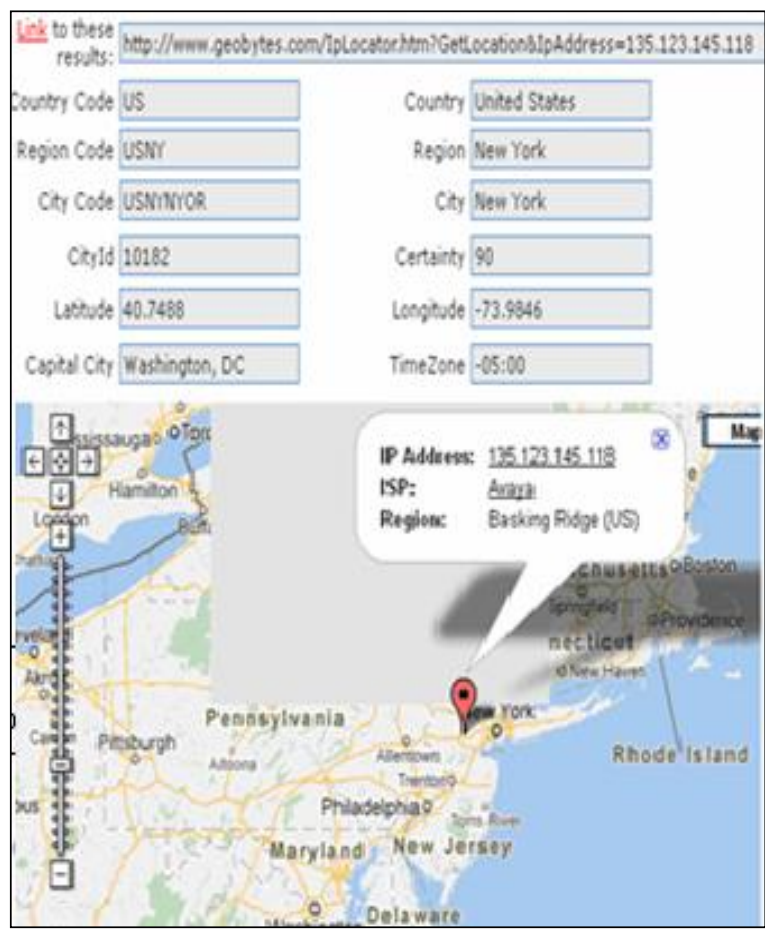

Fig 4: The Location including Longitude, Latitude, name of ISP service provider and city for given IP address. The Location is also shown using Google maps [18].

\section{Test Case 4: IP Address: 42.110.237.181}

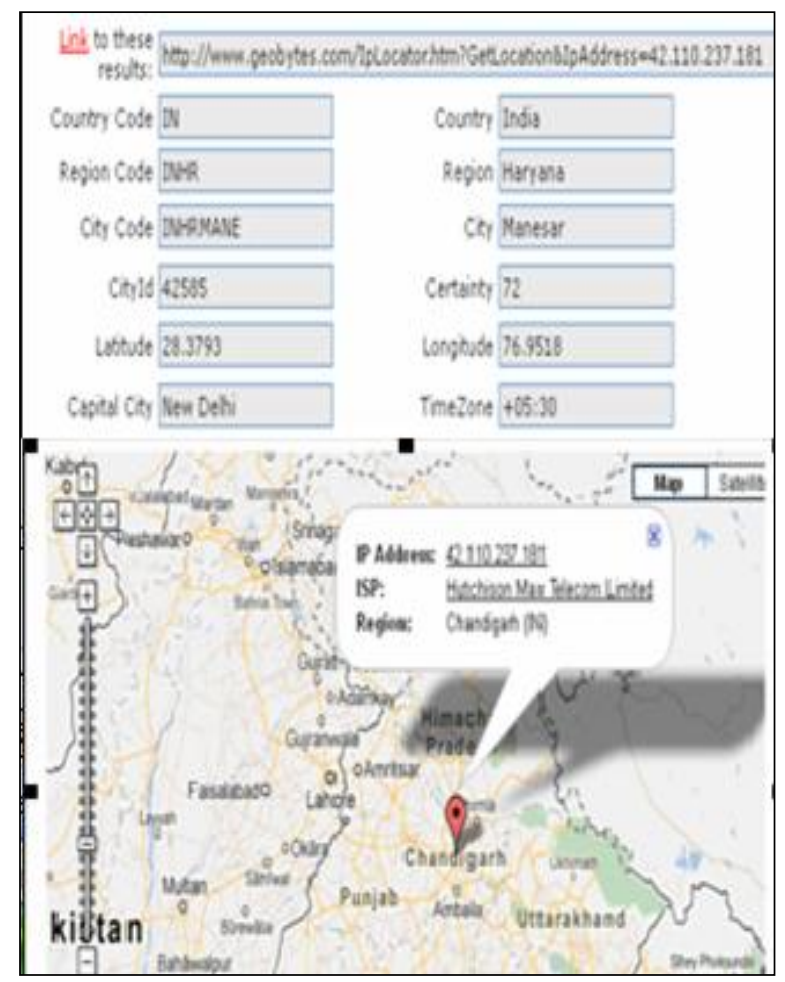

Fig 5: The Location including Longitude, Latitude, name of ISP service provider and city for given IP address. The Location is also shown using Google maps [18] 


\subsubsection{Limitations}

According to the results of Fig 2-5, it is observed that, the above Software does not provide the real time Location of a person. For example, if in the Morning, a person is in Delhi and in the evening, the same person is in Faridabad. This change over is not shown through this Service. Therefore, other software is tested to get the Location through Mobile Number. The Results are shown is Section 4.2.

\subsection{Location Tracking through Mobile Number}

The various Mobile numbers are tested to get the Location through Mobile number Tracker [9] using Google Maps [18]. Some of the test cases with results are shown below:-

Test case 1: Mobile No.: 7428299988

\begin{tabular}{|c|c|}
\hline Mobile No. & 7428299988 \\
\hline $\begin{array}{l}\text { Location: } \\
\text { Delhi } \\
\text { Signaling : } \\
\text { CDMA } \\
\text { Operator : } \\
\text { Reliance }\end{array}$ & 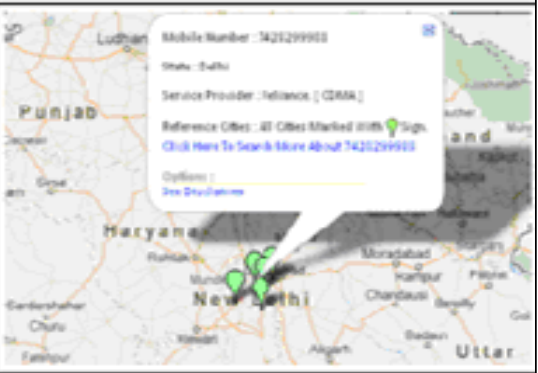 \\
\hline
\end{tabular}

Fig 6: showing Operator's name, Network CDMA and Location as Delhi. Location is also shown on using Google maps [18].

Test case 2: Mobile No.: 9810144169

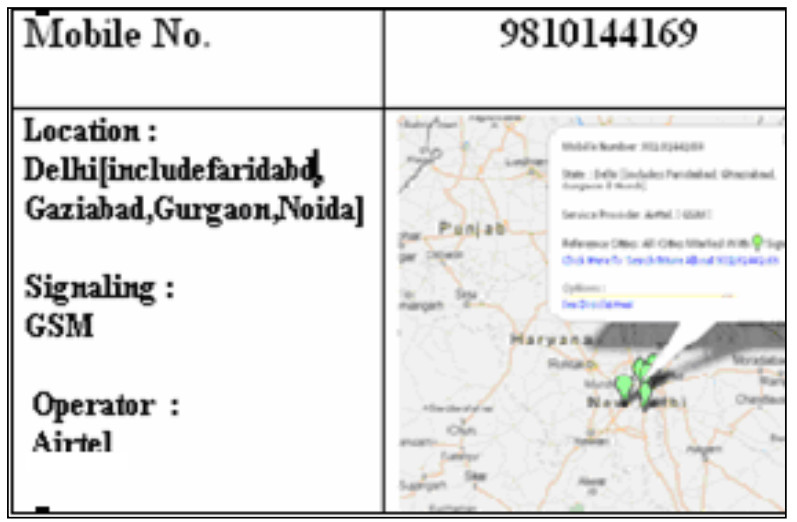

Fig 7: showing Operator's name, Network GSM and cities. Locations are also shown on using Google maps [18].

\subsubsection{Limitations}

As per results seen in Fig 6-7, it is observed that, the above Software does not provide the real time Location of User. It only shows the Operator, the network and the Location from where the Mobile is subscribed. For example, in fig 7, the location of mobile no. 9810144169 is checked, It shows the Location as a broad area of NCR i.e. Faridabad, Noida, Gurgaon which is not useful. One can't trace a person. Also, if someone mobile is subscribed in Faridabad and now he is in Punjab. This software does not show his Location of Punjab. It only shows faridabad.Therefore, next software is tested to get Location through Facebook.The results are shown in Section 4.3.

\subsection{Location Tracking through Facebook}

The Locations of some friends are tested through Facebook [10] to get the location. Two Test cases with the Location of two Friends are shown below.

\section{Test case 1: Friend1 in Scuba and Atuba}

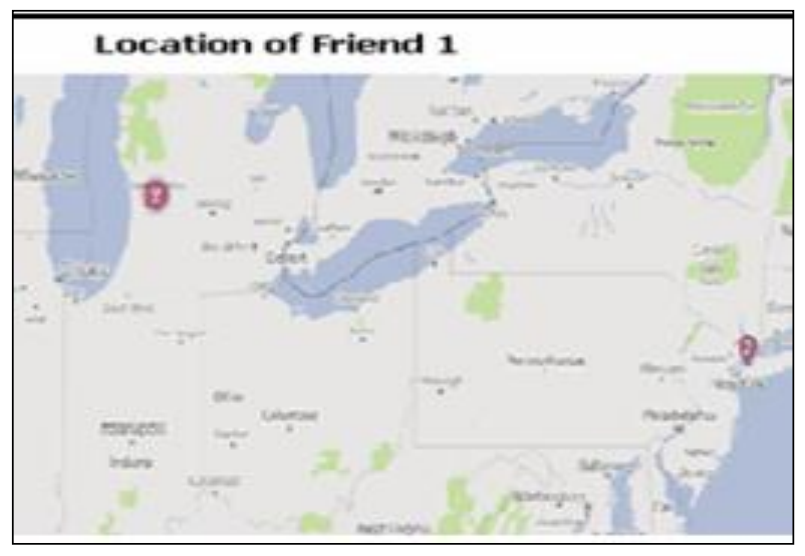

Fig 8: The two Locations of Friend 1 is Cities Atuba and Scuba in New York is shown using Google Maps[18].

Test case 2: Friend2 in Punchkula

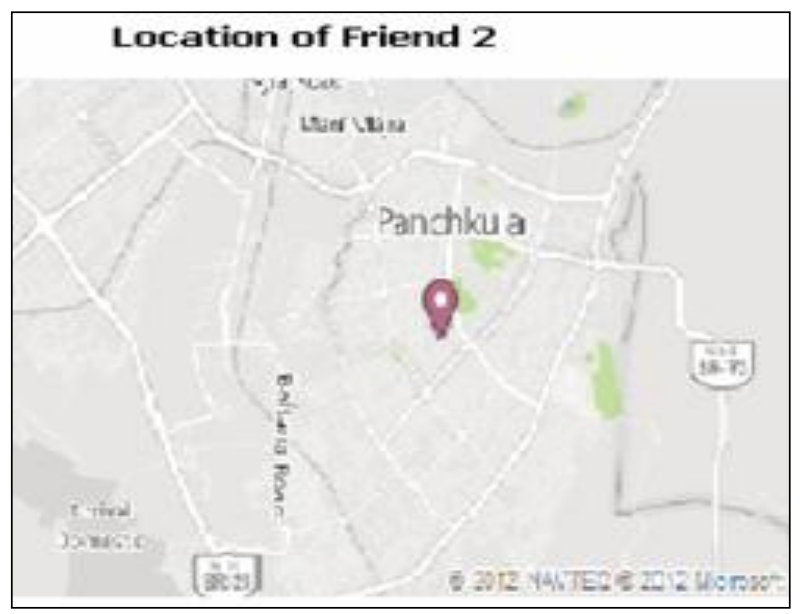

Fig 9: A Location of Friend 2 is City punchkula is shown using Google maps [18].

\subsubsection{Limitations}

From fig 8-9, it is observed that the Locations of Friends are provided, but according to the address they had given in their profile. It does not provide the current Location of Friends. For example as in Fig 9, the two Locations of friend 1 are shown as he had entered two addresses in his profile. But real location is not shown.

\section{The Summary of achieved Results:-}

The results of above Softwares gives the Location of Stationary User, it is also observed that the current location of friend is not detected. Therefore in section 5, other softwares are tested to get the current location of moving person through SMS. 


\subsection{Location Tracking through SMS}

This application runs after installed mobile phone for Location detection of moving user.

\subsubsection{How it Works}

The SMS Tracker [19] is an application runs on Person Mobile phone to detect the location. The Location is detected after installing an application on Idea Alcatel one touch 918N Mobile with Android 2.3 operating system. When a person sends or receives messages to and from one another, The location and SMS details of sender and receiver are stored in MySql database of Server through SMS gateway. The Server processed the data and the results are displayed on website and person mobile phone. The architecture of this software is shown in Figure 10.Figure 11 shows the details of incoming and outgoing messages of Mobile users with date and time and an option to check the location of sender and receiver.

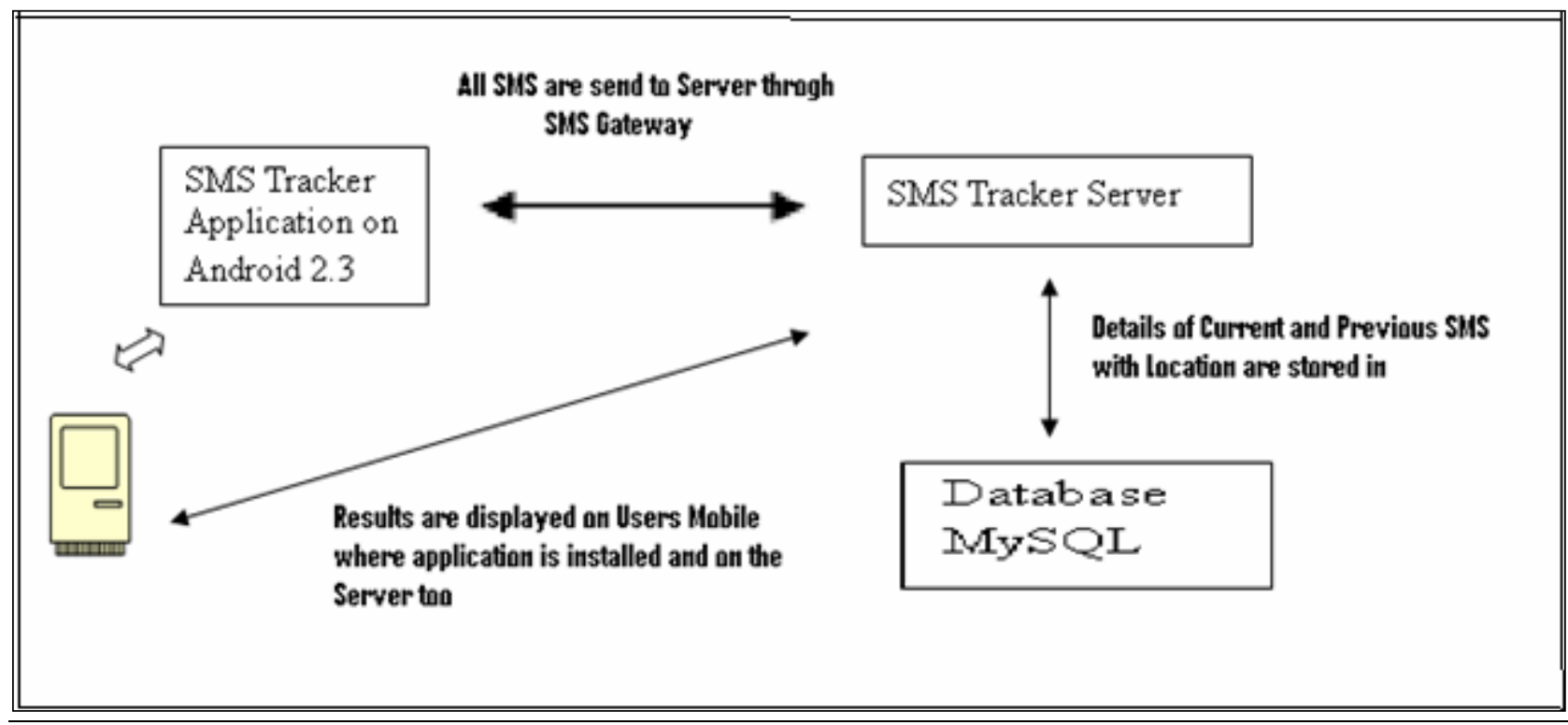

Fig 10: Architeture of SMS Tracker with location

The details of Location of a person are determined by sending SMS to each other. The Location is displayed on
Person's Mobile on which the Software is loaded as well as projected on the Web Server.

\begin{tabular}{|c|c|c|c|c|c|}
\hline \# & Time Date & From & To & Body & Location \\
\hline 1 & 5:27.01 PM July 13.2012 & $10.1 d e a$ & shelly & 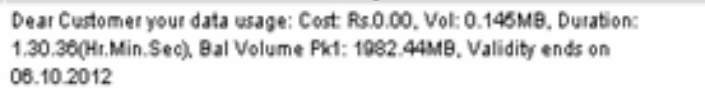 & No Location \\
\hline 2 & 5:26:21 PM July 13.2012 & shelly & 9810802829 & Hello:) d & No Location \\
\hline 3 & 4:80,80 PM July 12,2012 & shelly & Anupma & VoICE CALL duration: $\infty: 03: 62$ & View Map \\
\hline 4 & 42122 PM July 13,2012 & $10-1 d e a$ & shelly & 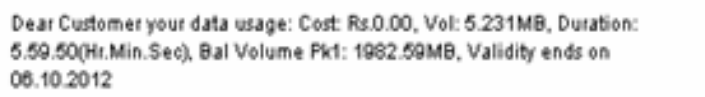 & No Location \\
\hline 5 & 3:17:35 PM July 13, 2012 & $10-1 d e a$ & shelly & $\begin{array}{l}\text { Dear Customet yout data usage: Cost: Rs:0.00, Vol: } 5.231 \mathrm{MB} \text {, Dutation: } \\
5.59 .50 \text { (Ht.Min.Sec), Bal Volume Fit: } 1982.59 \mathrm{M \theta} \text {, Validity ends on } \\
06.10 .2012\end{array}$ & View Map \\
\hline 6 & 9:26:16 AM July 13,2012 & shelle & Bisu & Hello & No Location \\
\hline 7 & 92132 AM July 13,2012 & Hubi & shellu & hi & View Map \\
\hline 8 & 9:17:22 AM July 13,2012 & $10 \cdot 1 d e a$ & shellu & $\begin{array}{l}\text { Dear Customer your data usage: Cost Rs:0.00. Vol: } 1.240 \mathrm{MB} \text {. Duration: } \\
5.59 .53 \text { (Pt.Min.Sec), Bal Volume Pkt: } 1987.82 \mathrm{MB} \text {, Validity ends on } \\
06.10 .2012\end{array}$ & View Map \\
\hline 9 & 9:14.58 AM July 13,2012 & shellu & Hubi & Hello & View Map \\
\hline 10 & 9.56:40 AM July 12,2012 & Hubi & shelly & hi & Viqu Map \\
\hline 11 & 322.25 AM July 13.2012 & 10.1 dea & shelly & 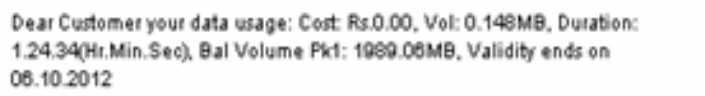 & No Location \\
\hline 12 & 1:42:45 AM July 13,2012 & $A D-650044$ & shellu & $\begin{array}{l}\text { Whas Ottert Recharge karein Rs111 se avr padyein poore } 222 \text { Local aur STD } \\
\text { minutes. Padk validity } 15 \text { din. }\end{array}$ & No Loestion \\
\hline 13 & 10:25:31 PM July 12, 2012 & +911409605392 & shelly & VOICE CALL - đuration: 00:00:18 & View Map \\
\hline
\end{tabular}

Fig 11: Results of incoming and out going messages including date, time and an option to see location [19] 
After clicking on the view map option of above results, the Location is detected including Latitude, Latitude, timestamp and a Google Map[18] showing current Location of sender and receiver. The details of few of them are shown in Figures 12-17.

Test case 1: Mobile No.: 9818856542

The results of this mobile no. are shown in Fig 12 \& Fig 13

\begin{tabular}{|l|l|}
\hline \multicolumn{2}{|c|}{ Location Details } \\
\hline Mobile & 9818856542 \\
\hline Time Stamp & $4: 30: 59$ p.m july 13.2012 \\
\hline Duration & $00: 03: 52$ \\
\hline Latitudc & 28.451757 \\
\hline Longitude & 77.284645 \\
\hline Accuracy & 1362 meters \\
\hline
\end{tabular}

Fig 12: Details of Mobile no. 9818856542 with Longitude, Latitude and accuracy limits.

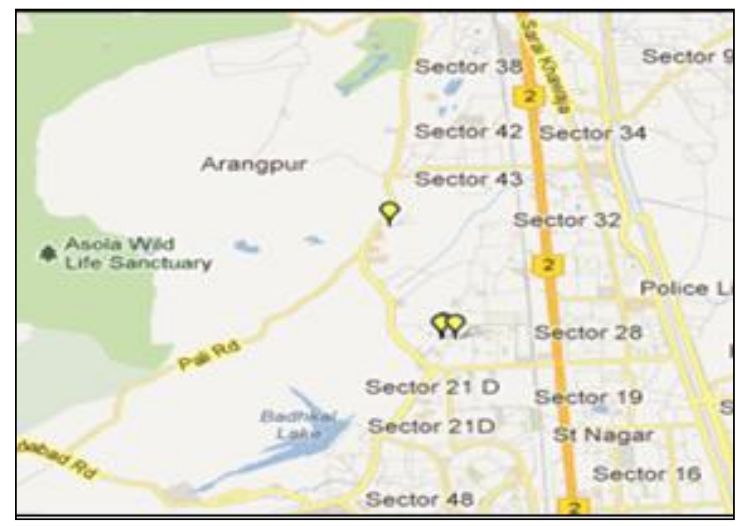

Fig 13: User with Mobile no. 9818856542 is present in Sector 21D is shown using Google maps [18].

Test case 2: Mobile No.: 9999378844

The results of this mobile no. is shown in Fig 14 \& Fig 15

\begin{tabular}{|l|l|}
\hline Mobile & 9999378844 \\
\hline Time Stamp & $7: 04: 03$ p.m july 12,2012 \\
\hline Duration & $00: 00: 56$ \\
\hline Latitude & 28.431684 \\
\hline Longitude & 77.294586 \\
\hline & \\
Accuracy & 36 meters \\
\hline
\end{tabular}

Fig 14: Details of Mobile no. 9999378844 with Longitude, Latitude and accuracy limits.

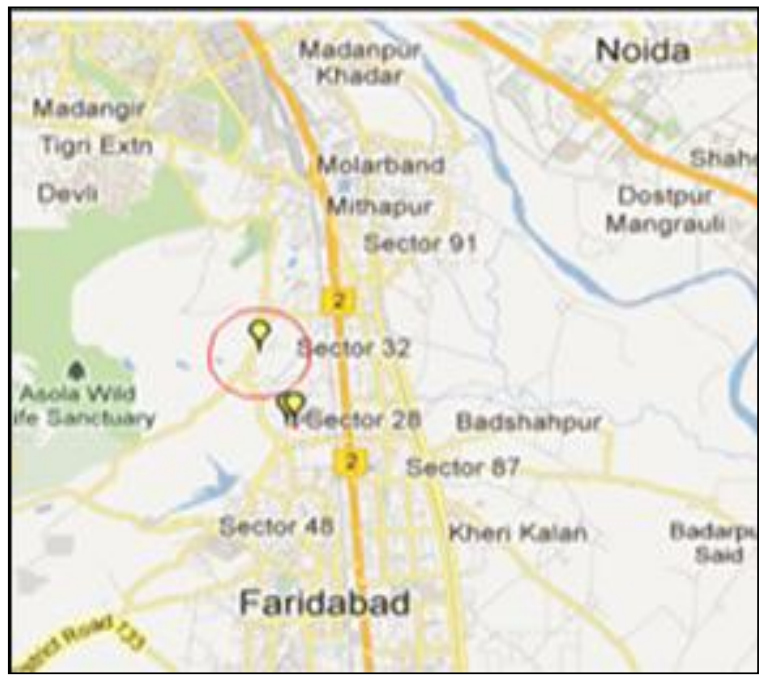

Fig 15: User with Mobile no. 9999378844 is present in Sector 32 is shown using Google Maps [18].

Test case 3: Mobile No.: 8800182889

The results of this mobile no. is shown in Fig 16 \& Fig 17

\begin{tabular}{|l|l|}
\hline \multicolumn{2}{|c|}{ Location Details } \\
\hline Mobile & \multicolumn{1}{|c|}{8800182889} \\
\hline Time Stamp & $4: 30: 59$ p.m july 13,2012 \\
\hline Duration & $00: 00: 11$ \\
\hline Latitude & 28.416183 \\
\hline Longitude & 77.324673 \\
\hline & 36 meters \\
\hline
\end{tabular}

Fig 16: Details of Mobile no. 8800182889 with Longitude, Latitude and accuracy limits.

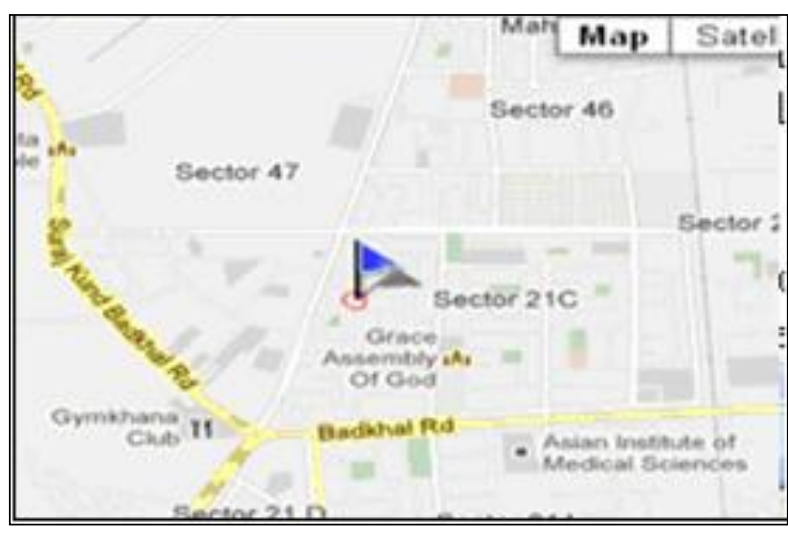

Fig 17: User with Mobile no. 8800182889 is present in Sector 21C is shown using Google Maps [18]. 


\subsubsection{Limitations}

As per the above results, this software provides a real time location of a mobile user. For example, if in morning a person is in Delhi and in evening, he is in Faridabad. The map shows the changeover from Delhi to Faridabad. But it has a limitation that it cannot display the nearby precise location for example, if a person lives a society of Sector 21C, it shows Sector $21 \mathrm{C}$ but does not show that Society.

\subsection{Location Tracking through Google Latitude}

Google latitude [6] is defined as a "Location aware mobile application developed by Google as a successor to its earlier SMS based service Dodge ball". This Software is tested with various Mobile users for Location detection. The Software is loaded on Idea Alcatel one touch 918N, version 6573.The software works with android 2.3 operating system loaded on mobile. This Software also gives the output of some queries like "show me the area where I am on the map", "show me the area where is my friend at this time". Google use their own Location databases for Localization [15]. In order to get the Location of user, Location Manager must be acquired from the system. Then a new Location Listener [14] object is assigned for each Mobile User. After that with requestLocation updates the device begins to locate the position. The Code to get the Location of user is shown below.

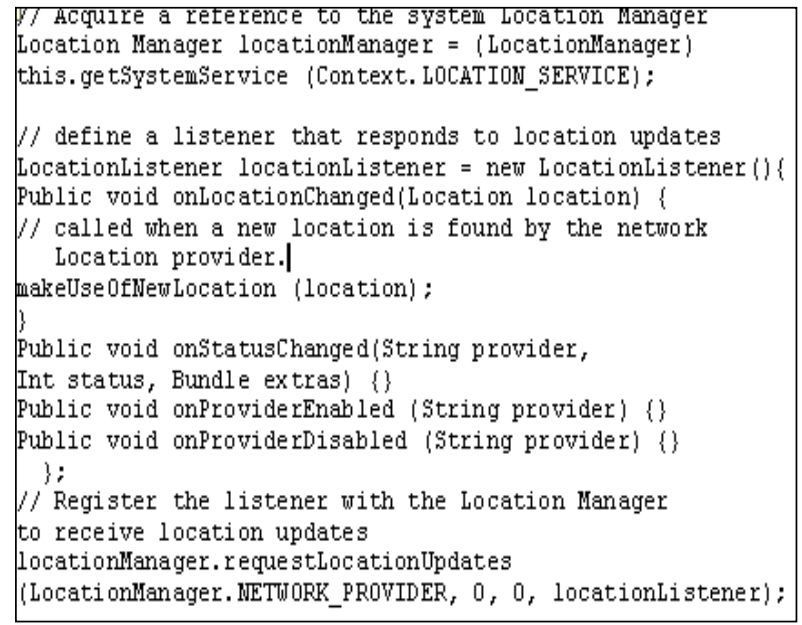

Fig 18: Location Listener and Location Provider in Android Operating system [14]

The Software is tested with various users having Idea Alcatel one touch $918 \mathrm{~N}$ Mobile. Few of them are shown. Here testing is shown with three persons i.e. Person A, B and C. Figure 19 shows Person A in Sector 45, Person B in sector 21C, and Person C in Sector 19, at their home Locations in morning. Figure 20, shows three of them in university in afternoon, it shows three of them in Sector 43 as university is Located in Sector 43.These results are summarized in Table 1 .

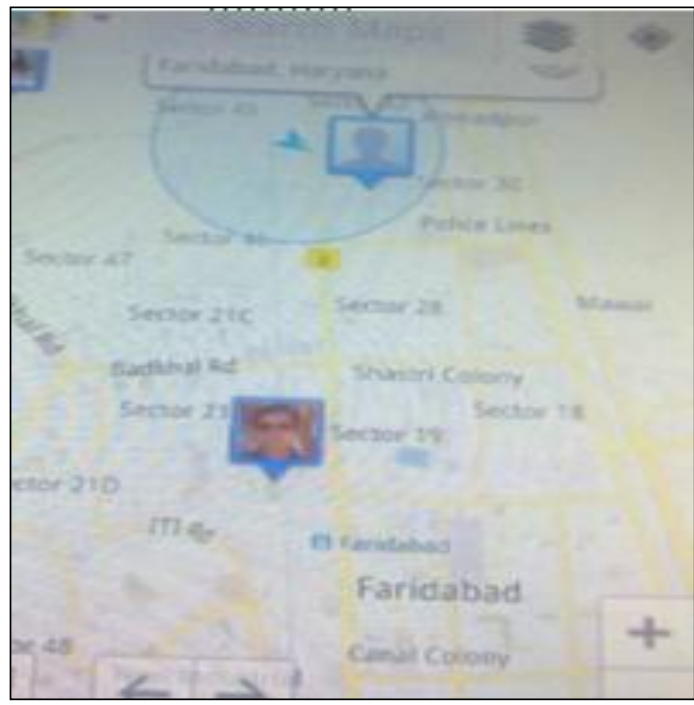

Fig 19: Real time location of a Person $A, B$ and $C$ at their home places with Google Latitude [6] using Idea Alcatel one touch 918N Mobile.

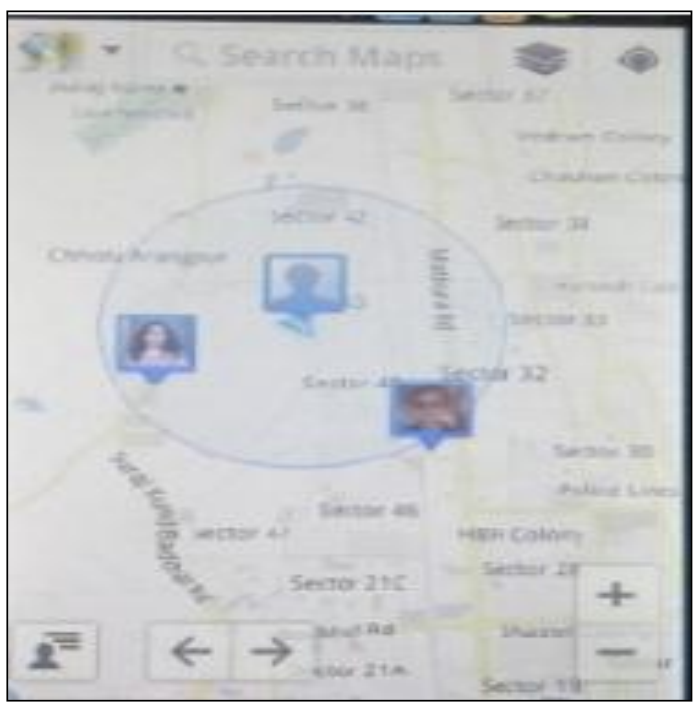

Fig 20: Real time location of Person $A, B$ and $C$ at same university in Sector 43 with Google Latitude [6] using Idea Alcatel one touch 918N Mobile.

From fig $19 \& 20$, the results are described in table 1.

\begin{tabular}{|l|l|l|}
\hline Name & $\begin{array}{l}\text { Day 1(in } \\
\text { (morning at } \\
\text { home places) }\end{array}$ & $\begin{array}{l}\text { Day 1 in } \\
\text { (afternoon } \\
\text { in university) }\end{array}$ \\
\hline Person A & Sector 45 & Sector 43 \\
\hline Person B & Sector 21C & Sector 43 \\
\hline Person C & Sector 19 & Sector 43 \\
\hline
\end{tabular}

Table 1: Result of Person A, Person B and person C on day1 in morning and afternoon. 


\subsubsection{Limitations}

As the results seen from above figures, the Location tracked is correct but there is a constraint, for example Fig 20 shows three of persons in same region, which is correct. Three of them are in University and in different departments. But the Figures does not show the locations of three in different departments, Figures only shows three of them in same University.

\section{CONCLUSION}

In this paper, the results of Stationary User using Softwares like Mobiletracker, IPAddress Locator and Facebook are shown with various test cases. The paper also shows the location of moving User with Softwares like SMS Tracking and Google latitude with test cases. This work is done as a part of designing an algorithm for Location detection in more precise way.

\section{REFERENCES}

[1] Dileepa Jayakody,"GPS/GSM based Train Tracking system-utilizing mobile support public transportation"journal of computing, march 2011, srilanka.

[2] Kee NeeGoh et al,"Architecture of GPS based Road Management System", Journal of applied sciences, pp $26-31,2011$

[3] Wikipedia,"Base Station Subsystem available at, http://en.wikipedia.org/wiki/Base_station_subsystem,retr ieved on 18 august, 2012.

[4] Maxmind,"Geolocation and online fraud prevention",http://www.maxmind.com/,retrieved on 2 July, 2012.

[5] Sipat Trukese et al,"Geolocating IP addresses in Cellular data networks", PAM'2012 proceedings of $13^{\text {th }}$ International conference on passive and active measurement, pp 158-167.

[6] Wikipedia,"Google latitude available at, http://en.wikipedia.org/wiki/google_latitude,retrieved on 17 August, 2012.
[7] Wikipedia,"Global positioning System" available at, http://en.wikipedia.org/wiki/Global_positioning_system,r etrieved on 18 August 2012.

[8] Geobytes,"IP address Locator" available at http://www.geobytes.com/iplocator.htm,retrieved on 2 July, 2012.

[9] Mobile Tracker,"Tracing Location of Mobile" available at http://mobilenumbertracker.co.in/" retrieved on 4 July, 2012.

[10] Facebook,"Map to display location of friends" available at http://Facebook.com retrieved on 10 July, 2012.

[11] Paranvir Behl et al,"User Location and Tracking Inbuilding radio Network", Microsoft Research, Feb 1999 , pp 1-12.

[12] F.Aloul et al,'Using Mobiles for On Campus Location Tracking"M0MM2009, Dec 2009.

[13] Mohammad Al-khedkar,"Hybrid GPS-GSM localization of automobile tracking system", International Journal of Computer Science and Information Technology, Vol 3, issue 6, Dec 2011, pp 75-85.

[14] Android Guide," Code for obtaining user location", http://developer.android.com/guide/topics/location/obtain ing-user-location.html,retrieved on July 2012.

[15] Denis Huber," Background Positioning for Mobile devices-Android vs. iphone", Joint Conference of IEEE computer \& communication Socities, 2011.

[16] Kuboye et al,"Optimization Models for minimizing congestion in Global System for Mobile Communications in Nigeria", Journal of Media and Communication Studies, Vol 2, issue 5, pp 122-126, 2010.

[17] Peter Rysavy,"Data capabilities for GSM evolution to UMTS", White Paper, November 19, 2002.

[18] Google," Web mapping", http://maps.google.com, retrieved on 15 July, 2012.

[19] Gizmoquip,"SMS Tracker", available at http://www.gizmoquip.com/smslog/,retreived on 15 July 2012. 